\title{
Visible Light Photocatalytic Properties of Ta and N Codoped $\mathrm{SrTiO}_{3}$ Nanoparticles
}

\author{
Uyi Sulaeman, Shu Yin, and Tsugio Sato \\ Institute of Multidisciplinary Research for Advanced Materials, Tohoku University, Sendai 980-8577, Japan \\ Correspondence should be addressed to Uyi Sulaeman, suyi@mail.tagen.tohoku.ac.jp
}

Received 6 September 2010; Revised 2 December 2010; Accepted 2 December 2010

Academic Editor: Gong Ru Lin

Copyright () 2010 Uyi Sulaeman et al. This is an open access article distributed under the Creative Commons Attribution License, which permits unrestricted use, distribution, and reproduction in any medium, provided the original work is properly cited.

Ta and $\mathrm{N}$ co-doped $\mathrm{SrTiO}_{3}$ was synthesized by microwave-assisted solvothermal reaction using $\mathrm{SrCl}_{2} \cdot 6 \mathrm{H}_{2} \mathrm{O}, \mathrm{Ti}\left(\mathrm{OC}_{3} \mathrm{H}_{7}\right)_{4}, \mathrm{TaCl}_{5}$, and HMT (hexamethylenetetramine) in $\mathrm{KOH}$ and oleic acid mixed solutions. The products were characterized by XRD, TG-DTA, BET surface area measurement, TEM, EDX, DRS, PL-Spectra, and XPS. The nanoparticles of perovskite-type $\operatorname{SrTi}_{1-x} \mathrm{Ta}_{x} \mathrm{O}_{3-y} \mathrm{~N}_{y}$ $(x=0-0.1)$ were successfully synthesized. The photocatalytic activity of $\mathrm{SrTiO}_{3}$ for $\mathrm{DeNO}_{x}$ ability in the visible light region could be improved by the codoping of $\mathrm{Ta}^{5+}$ and $\mathrm{N}^{3-}$. The excellent visible light photocatalytic activity of this substance may be due to the generation of a new band gap by doping nitrogen that enables the absorption of visible light as well as a decrease in the incidence of the lattice defects, which acts as a recombination center of photo-induced electrons and holes by codoping with $\mathrm{Ta}^{5+}$.

\section{Introduction}

Photocatalytic reaction using strontium titanate as an efficient photocatalyst is widely considered as an emerging technology for solving environmental problems to degrade organic contaminants $[1,2]$ and for water splitting to produce hydrogen as a renewable energy. However, the lack of visible light photocatalytic activity of $\mathrm{SrTiO}_{3}$ due to wide band gap semiconductors is a problem in solar energy utilization. Therefore, a great effort has been put towards extending their absorption and conversion capacities into the visible range [3]. Recently, it was discovered that doping with an anion such as $\mathrm{N}$ into $\mathrm{SrTiO}_{3}$ leads to an extension of the optical absorption to the visible light region $[4,5]$.

Nitrogen doping to titania photocatalyst has been proven to be an effective method for extending the photoactive region to visible light range via narrowing the band gap. This is because the visible light sensitivity is originated from the isolated narrow band derived from the dopant anion porbital [6]. However, nitrogen doping to substitute oxygen in a photocatalyst will lead to the formation of lattice defects for charge compensation which act as recombination centers of photo-induced electrons and holes. To decrease the incidence of the lattice defect, we designed codoping of a metal ion and nitrogen into $\mathrm{SrTiO}_{3}$. Previous work had also shown that lanthanum and nitrogen codoped $\mathrm{SrTiO}_{3}$ could enhance the photocatalytic ability in visible light [7].

To improve the ability of photocatalytic activity, codoping with higher valence metal ion $\left(\mathrm{Ta}^{5+}\right)$ to the $\mathrm{Ti}^{4+}$ site in nitrogen doped $\mathrm{SrTiO}_{3}$ may have great potential to reduce the incidence of the lattice defect and suppress the electronhole recombination. It is well known that $\mathrm{Ta}^{5+}$ can substitute $\mathrm{Ti}^{4+}$ in $\mathrm{SrTiO}_{3}$ without large lattice strain because of the similar ionic radius. Therefore, it is expected that codoping of $\mathrm{Ta}^{5+}$ and $\mathrm{N}^{3-}$ in $\mathrm{SrTiO}_{3}$ may decrease the band gap energy without forming a lattice defect or lattice strain, consequently leading to generating high visible light photocatalytic activity. In this paper, we report the enhancement of visible light sensitivity in $\mathrm{Ta}$ and $\mathrm{N}$ codoped $\mathrm{SrTiO}_{3}$ synthesized by microwave-assisted solvothermal reactions at $200^{\circ} \mathrm{C}$.

Solvothermal synthesis is one of the simple methods to prepare fine particles with high crystallinity and a large specific surface area. In principle, the smaller the size, the higher the activity of the photocatalyst. However, a catalyst with a smaller dimension always accompanies a stronger tendency of aggregation, coupled with tremendous difficulties in separation, recovery, and recycling in industrial applications [8]. Therefore, modification of the preparation method is a great strategy to produce high quality crystals. In this paper, we report the synthesis of $\mathrm{Ta}$ and $\mathrm{N}$ codoped 


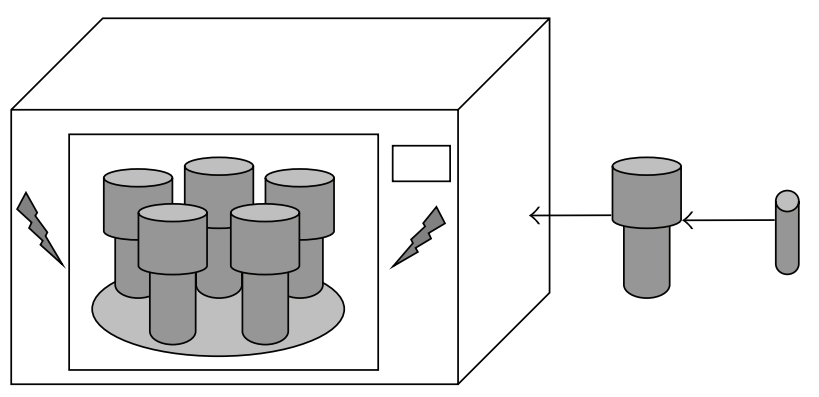

(b)

(a)

Figure 1: Microwave-assisted solvothermal reaction apparatus (a) Teflon reaction vessel, (b) microwave reaction apparatus (ACTAC Co., MWS-2).

$\mathrm{SrTIO}_{3}$ in a $\mathrm{KOH}$ methanol solution with the addition of oleic acid. Oleic acid is the surfactant which can be used to prepare nanocrystals with excellent particle size distribution [9]. Photodegradation of $\mathrm{NO}_{x}$ was employed to evaluate the photocatalytic activities of the Ta and $\mathrm{N}$ codoped $\mathrm{SrTiO}_{3}$ with different Ta contents under LED illumination $(\lambda=$ $390 \mathrm{~nm}, 445 \mathrm{~nm}, 530 \mathrm{~nm}$, and $627 \mathrm{~nm}$ ). It was demonstrated that these samples exhibited excellent visible light photocatalytic activities. The experimental results showed that a small concentration of Ta doping greatly improved the photocatalytic activity of $\mathrm{N}$ doped $\mathrm{SrTiO}_{3}$.

\section{Experimental}

2.1. Synthesis. The $\mathrm{Ta}$ and $\mathrm{N}$ codoped $\mathrm{SrTiO}_{3}, \mathrm{SrTi}_{1-x}$ $\mathrm{Ta}_{x} \mathrm{O}_{3-y} \mathrm{~N}_{y}$, with $x=0,0.02,0.05$, and 0.1 were synthesized by a solvothermal method. Titanium tetraisopropoxide, $\mathrm{Ti}\left(\mathrm{OC}_{3} \mathrm{H}_{7}\right)_{4}$, and $\mathrm{TaCl}_{5}$ were dissolved in 2-propanol and ethanol, respectively. After mixing these solutions, $\mathrm{SrCl}_{2} \cdot 6 \mathrm{H}_{2} \mathrm{O}$ was dissolved into the mixed-solution under vigorous stirring, followed by adding the mixed solution of $10 \mathrm{~mL}$ of $2 \mathrm{M} \mathrm{KOH}$ methanol solution, $1 \mathrm{~mL}$ of oleic acid, $1 \mathrm{~mL}$ of water, and $5 \mathrm{~g}$ of HMT (hexamethylentetramine). After that, the mixed solution was transferred to a Teflon reaction vessel with $70 \mathrm{~cm}^{3}$ of internal volume and irradiated by microwaves to start the solvothermal reaction at $200^{\circ} \mathrm{C}$ for $3 \mathrm{~h}$ using a microwave reaction apparatus (Figure 1). The microwave reaction system was operated at a frequency of $2.45 \mathrm{GHz}$ and a power of $900 \mathrm{~W}$ (90\% of full power). After cooling, the powder product was separated by centrifugation, washed with distilled water and acetone three times, respectively, dried in a vacuum at $60^{\circ} \mathrm{C}$ overnight, and then calcined at $300^{\circ} \mathrm{C}$ in air for $1 \mathrm{~h}$.

2.2. Characterization. The powder product was characterized by TG-DTA (Rigaku Thermo Plus TG-8120) and XRD (Shimadzu XD-D1) using graphite-monochromized $\mathrm{CuK} \alpha$ radiation. The lattice constant was determined using $\mathrm{Si}$ as an internal standard. Microstructures were observed by a transmission electron micrograph (TEM, JEOL JEM-2010). The chemical compositions were analyzed by EDX (Shimadzu, EDX-800HS). The specific surface areas were determined by the nitrogen adsorption at $77 \mathrm{~K}$ (BET, Quantachrome NOVA 4200e). The absorption edges and band gap energies of the products were determined from the onsets of diffuse reflectance spectra of the samples measured using a UVvis spectrophotometer (Shimadzu UV-2000). The PL spectra were analyzed by spectrofluorophotometer (Shimadzu, RF$5300 \mathrm{PC}$ ). The binding energies of doped ions were analyzed at room temperature by an X-ray electron spectrometer (Perkin-Elmer PHI5600).

2.3. Photocatalytic Activity Evaluation. Photocatalytic activity for the oxidative destruction of nitrogen monoxide was determined using a flow-type reactor, as shown in Figure 2, by measuring the concentration of $\mathrm{NO}$ gas at the outlet of the reactor $\left(373 \mathrm{~cm}^{3}\right)$ during photoirradiation on a constant flow of $1 \mathrm{ppm}$ NO-50 vol.\% air (balanced $\mathrm{N}_{2}$ ) mixed gas $\left(200 \mathrm{~cm}^{3} \mathrm{~min}^{-1}\right)$ [10]. The photocatalyst sample was placed in a hollow of $20 \mathrm{~mm}$ in length, $16 \mathrm{~mm}$ in width, and $0.5 \mathrm{~mm}$ in depth on a glass holder plate and set in the bottom center of the reactor. Photocatalytic activities were determined using different wavelengths of LED lamps of $390 \mathrm{~nm}$ (UV LED), $445 \mathrm{~nm}$ (blue LED), $530 \mathrm{~nm}$ (green LED), and $627 \mathrm{~nm}$ (red LED) at the same light irradiation intensity of $2 \mathrm{~mW} / \mathrm{m}^{2}$ by controlling the distance between the lamps and samples. The concentration of $\mathrm{NO}_{x}$ was determined using an $\mathrm{NO}_{x}$ analyzer (Yanaco, ECL-88A).

\section{Results and Discussion}

3.1. Structure, Phase, and Morphology of Catalyst. The XRD patterns of the powders obtained in the $\mathrm{KOH}$ and oleic acid mixed methanol solution followed by calcinations at $300^{\circ} \mathrm{C}$ in air for $1 \mathrm{~h}$ are shown in Figure 3. All diffraction peaks can be assigned to the perovskite-type structure having cubic symmetry according to JCPDS no.79-0176. It can be seen that the lattice constant slightly increased by an increase in the Ta content, indicating that $\mathrm{Ta}^{5+}$ was incorporated into the $\mathrm{Ti}^{4+}$ site of $\mathrm{SrTiO}_{3}$, since the ionic radius of six coordinated $\mathrm{Ta}^{5+}(0.064 \mathrm{~nm})$ is larger than that of $\mathrm{Ti}^{4+}(0.0605 \mathrm{~nm})$ but much smaller than that of $\mathrm{Sr}^{2+}(0.118 \mathrm{~nm})$.

Figure 4 shows the TG-DTA profiles of Ta and N codoped $\mathrm{SrTiO}_{3}(x=0.05)$. The sample showed three steps of weight losses. The first step of weight loss of ca. $2.4 \%$ up to $200^{\circ} \mathrm{C}$ may be due to the evaporation of adsorbed water and methanol. The second step weight loss around $10.3 \%$ up to $700^{\circ} \mathrm{C}$ may be due to the decomposition of organics. The exothermic peak around $287.4^{\circ} \mathrm{C}$ may be attributed to the oxidation of organics adsorbed on the catalyst. The third step of weight loss around $12.7 \%$ up to $1000^{\circ} \mathrm{C}$ may be due to the elimination of other more stable elements such as $\mathrm{OH}^{-}, \mathrm{N}^{3-}$, and carbon doped in the lattice of the perovskite structure.

The BET-specific surface area, particle size, and $\mathrm{Ta} / \mathrm{Ti}$ and $\mathrm{Ti} / \mathrm{Sr}$ atomic ratio determined by EDX analysis of the products are listed in Table 1. The particle sizes decreased and the specific surface areas increased with an increase in $\mathrm{Ta}$ content. It was found that the $\mathrm{Ta} / \mathrm{Ti}$ atomic ratios determined were almost identical to those added in the starting solution. However, the atomic ratios of $\mathrm{Ti} / \mathrm{Sr}$ in the samples of $x=0$ 


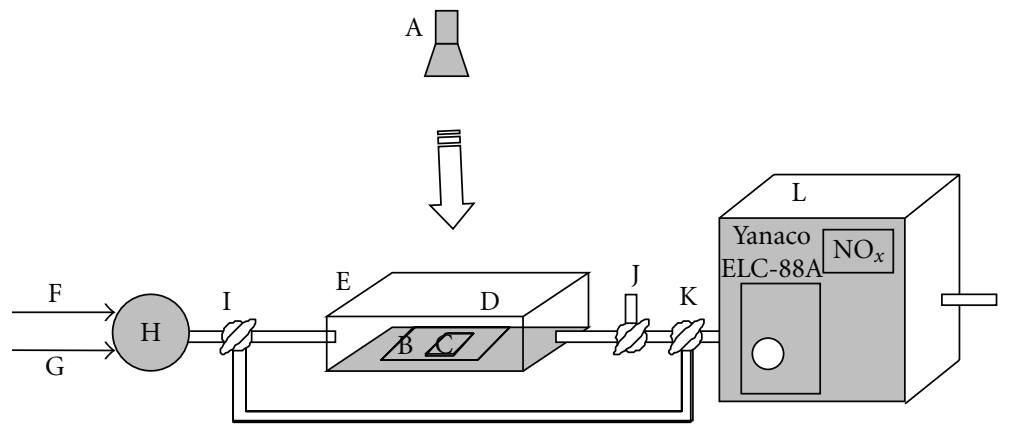

FIgUre 2: Photocatalytic reaction apparatus, A: $\operatorname{LED} \operatorname{lamp}(\lambda=627,530,445$, and $390 \mathrm{~nm})$, B: glass holder, C: catalyst $(20 \times 16 \times 0.5 \mathrm{~mm})$, D: colorless and transparent quartz cover, E: sealed opaque reactor (plastic, $373 \mathrm{~cm}^{3}$ ), F: 2 ppm standard NO gas (flow rate: $100 \mathrm{~mL} / \mathrm{min}$ ), G: dried air (flow rate: $100 \mathrm{~mL} / \mathrm{min}$ ), H: gas mixer, I, J, K: three-way cock, L: $\mathrm{NO}_{x}$ analyzer (Yanaco, ECL-88A).

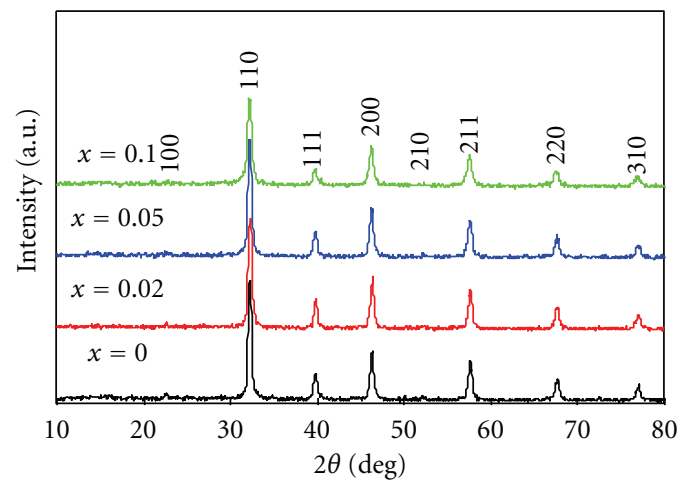

(a)

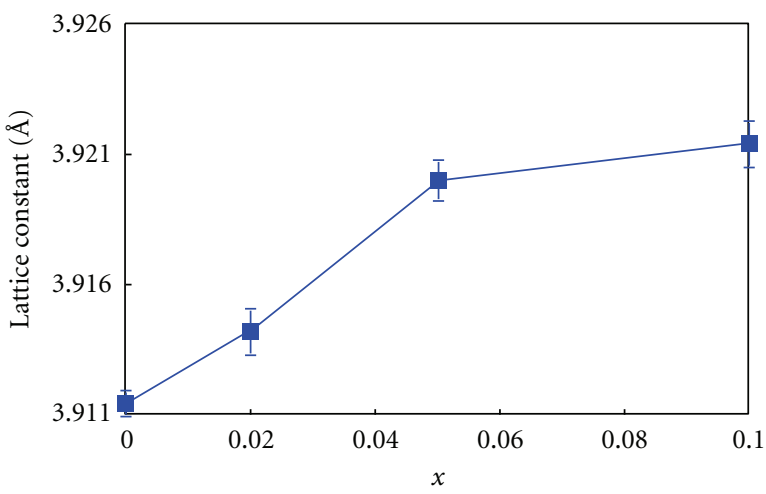

(b)

FIGURE 3: XRD patterns (a) and lattice constant (b) of $\mathrm{SrTi}_{1-x} \mathrm{Ta}_{x} \mathrm{O}_{3-y} \mathrm{~N}_{y}$.

and 0.02 were lower than the initial ones. This may be due to the experimental error in EDX analysis.

The morphologies of $\mathrm{Ta}$ and $\mathrm{N}$ codoped $\mathrm{SrTiO}_{3}$ formed by the microwave-assisted solvothermal method are shown in Figure 5. The average diameter was about $20 \mathrm{~nm}$. This value agrees with the particle sizes calculated by Scherrer's equation (see Table 1), indicating the particles were single crystals. The crystal size of $\mathrm{SrTiO}_{3}$ slightly decreased with an increase in $\mathrm{Ta}$ content. It can also be seen that the

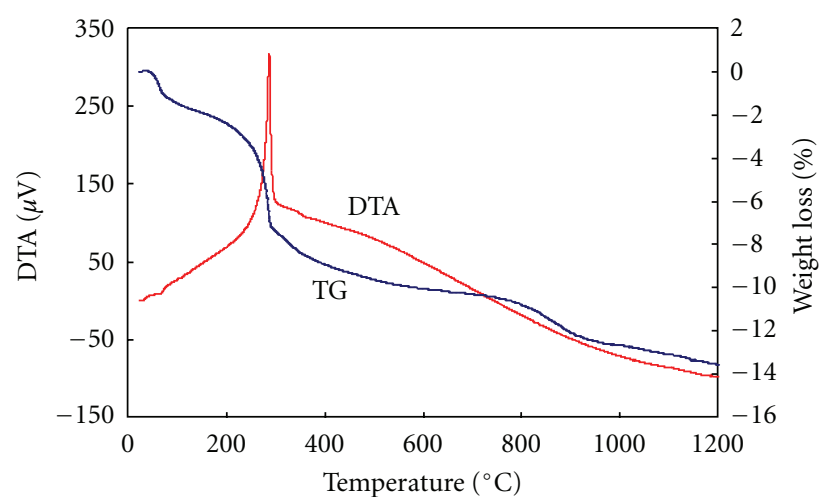

FIgUre 4: TG-DTA profiles of $\mathrm{SrTi}_{1-x} \mathrm{Ta}_{x} \mathrm{O}_{3-y} \mathrm{~N}_{y}(x=0.05)$.

TAble 1: Specific surface area, particle size, and $\mathrm{Ti} / \mathrm{Sr}$ and $\mathrm{Ta} / \mathrm{Ti}$ atomic ratios determined by EDX analysis of $\mathrm{SrTi}_{1-x} \mathrm{Ta}_{x} \mathrm{O}_{3-y} \mathrm{~N}_{y}$.

\begin{tabular}{lcccc}
\hline $\begin{array}{l}x \text { in the initial } \\
\text { solution }\end{array}$ & Particle size* $(\mathrm{nm})$ & S.S.A $\left(\mathrm{m}^{2} / \mathrm{g}\right)$ & \multicolumn{2}{c}{ EDX Analysis } \\
$\mathrm{Ti} / \mathrm{Sr}$ & $\mathrm{Ta} / \mathrm{Ti}$ \\
\hline$x=0$ & 19.6 & 51.0 & 0.89 & 0 \\
$x=0.02$ & 19.6 & 55.0 & 0.90 & 0.016 \\
$x=0.05$ & 18.1 & 55.6 & 0.92 & 0.049 \\
$x=0.10$ & 17.2 & 68.9 & 0.90 & 0.102 \\
\hline
\end{tabular}

* determined by Scherrer's method.

agglomeration of the particles was promoted by the decrease in the crystallite size.

3.2. Diffuse Reflectance and PL Spectra. Figure 6 shows the absorption spectra of the samples of $\mathrm{Ta}$ and $\mathrm{N}$ codoped $\mathrm{SrTiO}_{3}$. All samples showed absorption edges around 380$390 \mathrm{~nm}$ corresponding to the band gap energy of $\mathrm{SrTiO}_{3}$ and also have new absorption edges around 400-500 nm. The absorption around $400-500 \mathrm{~nm}$ may be attributed to the generation of a new band gap by nitrogen-doping. The absorption in the range of 400-500 $\mathrm{nm}$ increased with an increase in Ta content, indicating that the nitrogen doping was improved by codoping with $\mathrm{Ta}^{5+}$. 


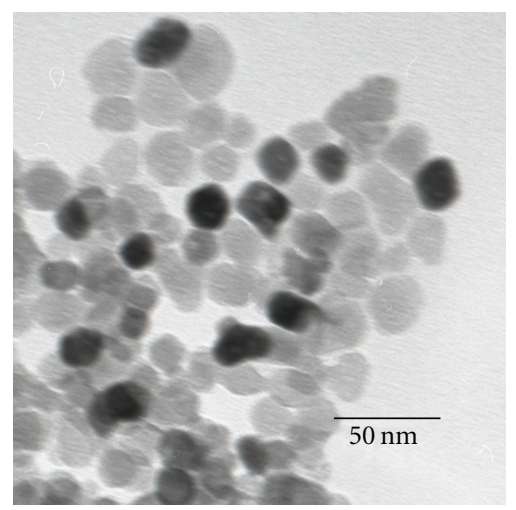

(a)

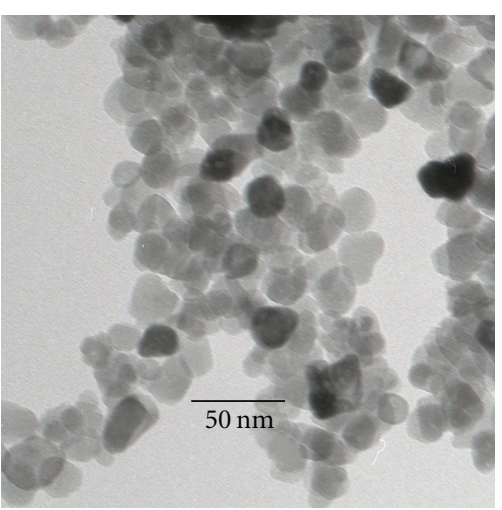

(b)

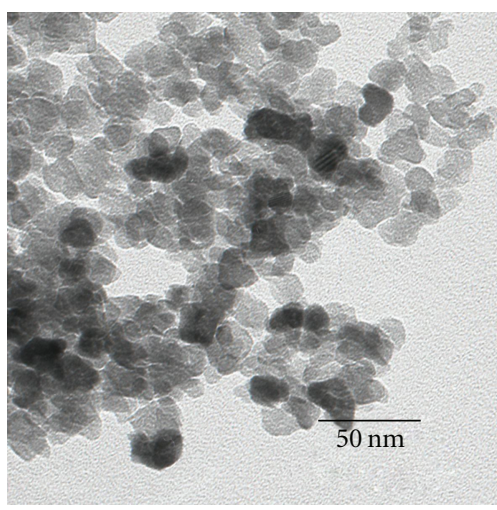

(c)

Figure 5: TEM images of $\operatorname{SrTi}_{1-x} \mathrm{Ta}_{x} \mathrm{O}_{3-y} \mathrm{~N}_{y}$, (a) $x=0$, (b) $x=0.05$, and (c) $x=0.1$.

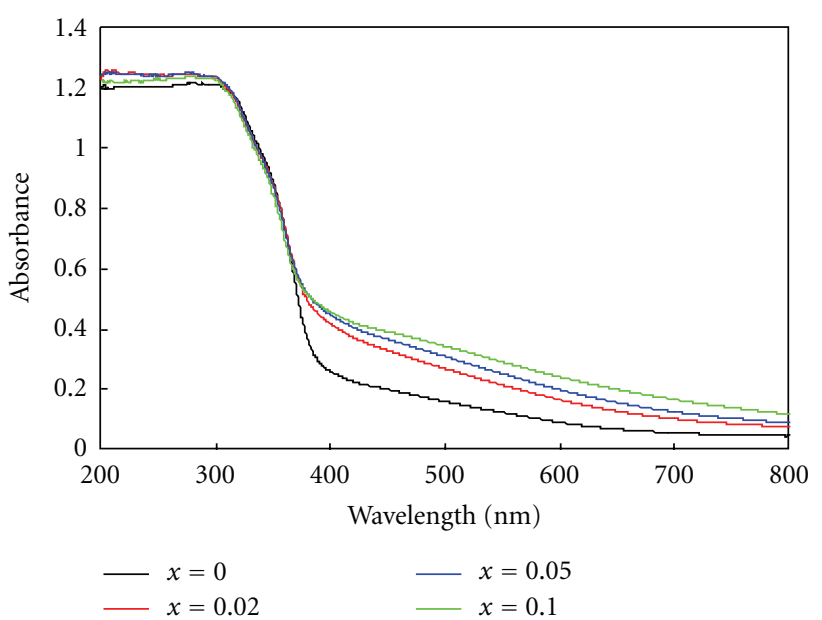

Figure 6: Diffuse reflectance spectra of $\mathrm{SrTi}_{1-x} \mathrm{Ta}_{x} \mathrm{O}_{3-y} \mathrm{~N}_{y}$ powders $(x=0-0.1)$.

Figure 7 shows the PL spectra of $\mathrm{Ta}$ and $\mathrm{N}$ codoped $\mathrm{SrTiO}_{3}$ with variation of Ta content. All measurements were carried out at room temperature and the samples were excited by UV light at $254 \mathrm{~nm}$. The samples exhibited peaks at $372,400,453$, and $470 \mathrm{~nm}$. The $400 \mathrm{~nm}$ and $470 \mathrm{~nm}$ bands may be attributed to neutral oxygen vacancies which are some intrinsic oxygen deficiencies in the samples [11]. It can be seen that the peak intensity at $372 \mathrm{~nm}$ of the sample with high Ta content $(x=0.1)$ increased, although the peak intensity at $470 \mathrm{~nm}$ did not change so much. This may be due to the promotion of recombination of photo-induced electrons and holes.

3.3. XPS Analysis. Figure 8 shows the XPS spectra of Ta and $\mathrm{N}$ codoped $\mathrm{SrTiO}_{3}$ after $\mathrm{Ar}^{+}$sputtering at $3 \mathrm{kV}$ for $3 \mathrm{~min}$. Figure 8 (a) shows the Ti3p peak energy, the peaks at 457.2, 457.5 , and $457.5 \mathrm{eV}$ are assigned as Ti3 $\mathrm{p}_{3 / 2}$ of $x=0, x=0.05$, and $x=0.1$, respectively. Due to the relatively big difference in ionic size between $\mathrm{N}^{3-}(r=0.171 \mathrm{~nm})$ and $\mathrm{O}^{2-}(r=$ $0.140 \mathrm{~nm}$ ), it was very difficult to substitute the oxygen atom

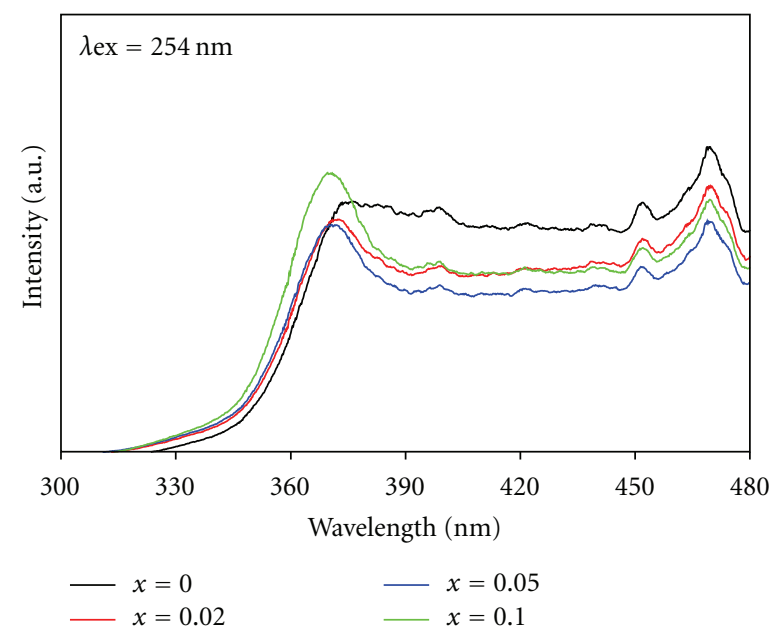

Figure 7: PL spectra of $\operatorname{SrTi}_{1-x} \mathrm{Ta}_{x} \mathrm{O}_{3-y} \mathrm{~N}_{y}$ powders $(x=0-0.1)$.

by nitrogen atom. The N1s XPS spectra of the samples are shown in Figure 8(b). The peak around $400 \mathrm{eV}$ and $398 \mathrm{eV}$ may be attributed to the $\mathrm{NH}_{3}$ and $\mathrm{N}_{2}$ adsorbed on the surface and doped nitrogen, respectively [12]. The sample with $x=0$ did not show the N1s peak at $398 \mathrm{eV}$, indicating a very low concentration of nitrogen doped in the lattice. Since in a previous paper [5], N-doped $\mathrm{SrTiO}_{3}$ prepared without oleic acid showed the peak at $398 \mathrm{eV}$ clearly, the doping of nitrogen may be depressed in the presence of oleic acid. The depression of nitrogen doping with oleic acid may be due to the surface modification of $\mathrm{SrTiO}_{3}$ by chemically adsorbed oleic acid. In contrast, the sample with $x=0.05$ showed clear peak at $398 \mathrm{eV}$, indicating that the nitrogen doping was promoted by codoping with $\mathrm{Ta}^{5+}$. This may be due to the decrease of the oxygen vacancy by codoping of $\mathrm{N}^{3-}$ and $\mathrm{Ta}^{5+}$ in a perovskite structure. The sample with $x=0.1$ showed the broad peak of N1s, although it showed the highest absorption in the visible light region as shown in Figure 6. Figure 8(c) shows the Ta4f spectra of the sample $(x=0.05$ and 0.1$)$. The peaks of $\mathrm{Ta}_{4} \mathrm{f}_{7 / 2}$ at $21.5,26.6,25.7$ for the Ta metal, $\mathrm{Ta}_{2} \mathrm{O}_{5}$ and $\mathrm{Ta}$ doped $\mathrm{SrTiO}_{3}$, respectively, were 


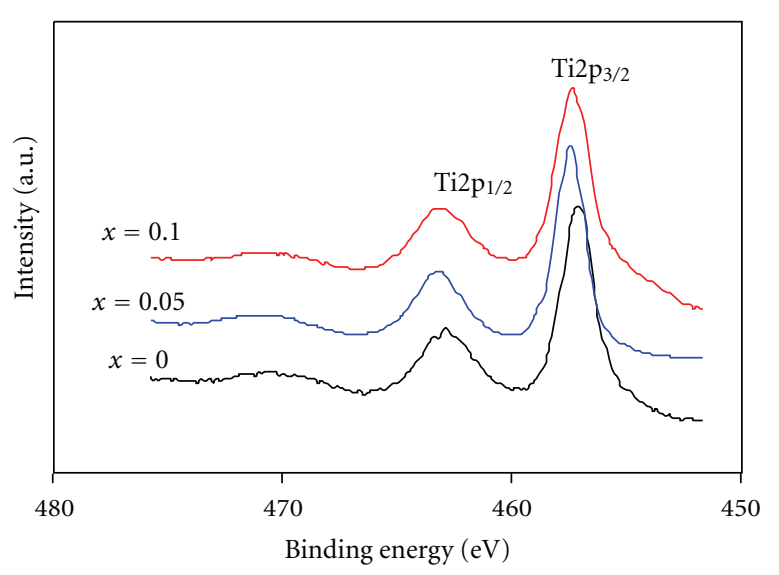

(a)

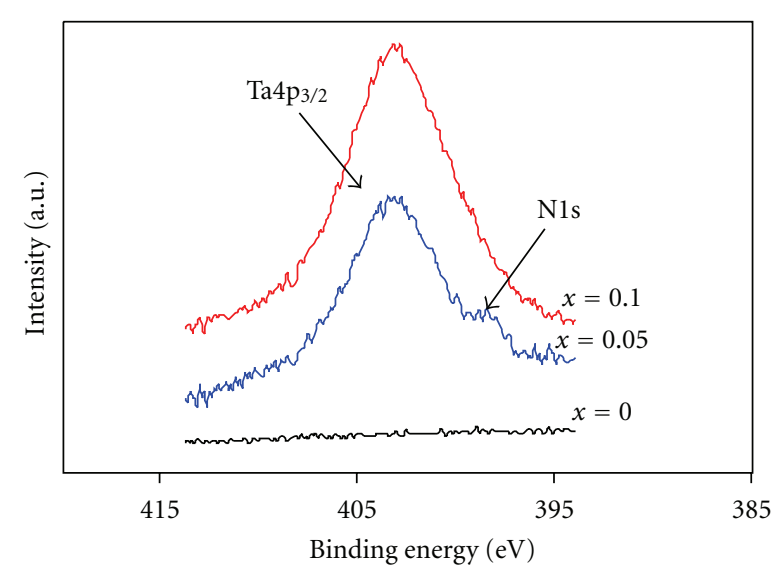

(b)

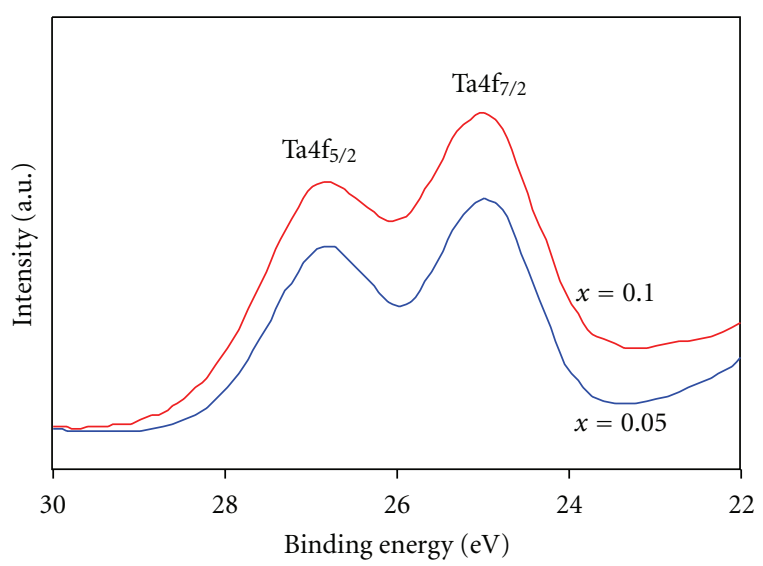

(c)

FIGURE 8: X-ray photoemission spectra of $\mathrm{SrTi}_{1-x} \mathrm{Ta}_{x} \mathrm{O}_{3-y} \mathrm{~N}_{y}(x=0,0.05,0.1)$, Ti2p (a), Ta4p (b), and Ta4f (c).

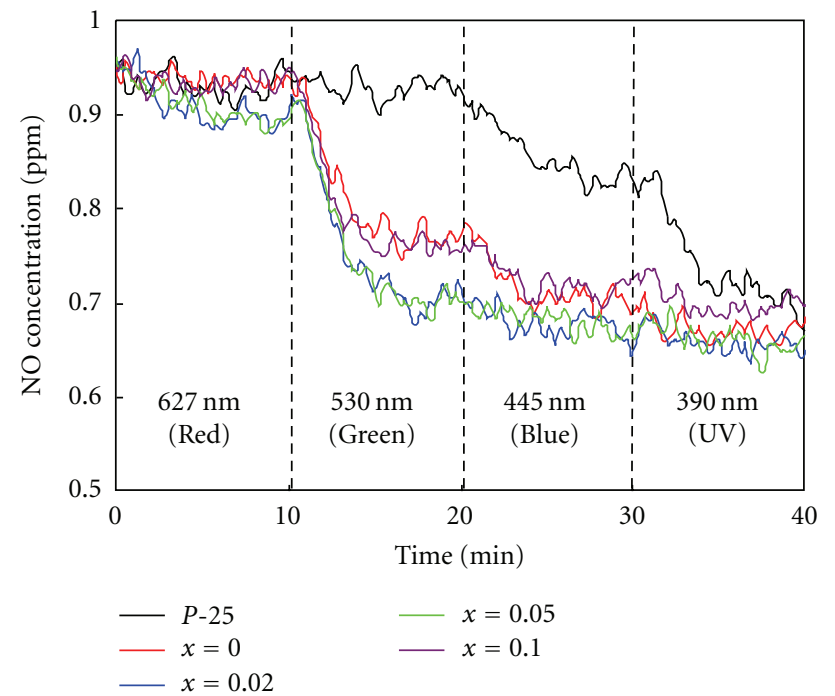

(a)

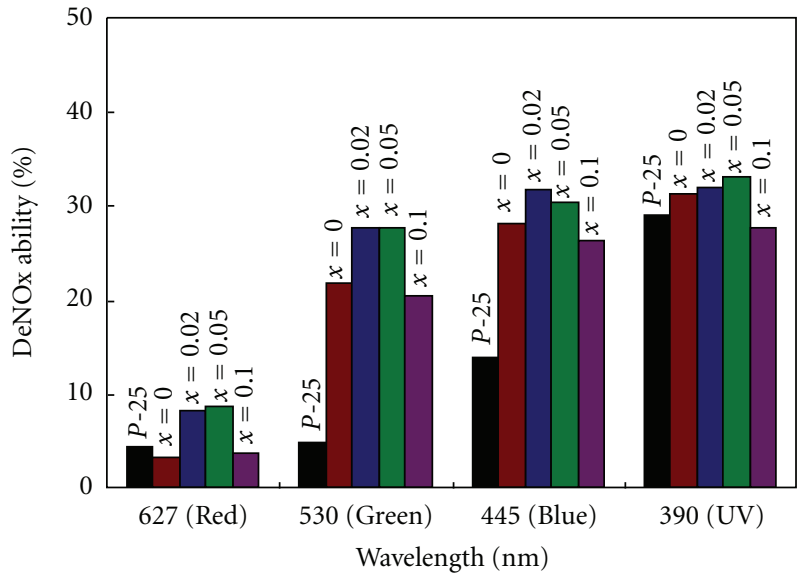

(b)

FIgURE 9: Photocatalytic activity of $\operatorname{SrTi}_{1-x} \mathrm{Ta}_{x} \mathrm{O}_{3-y} \mathrm{~N}_{y}$. 
reported by Varhegyi et al. [13]. The peaks at $25.0 \mathrm{eV}$ and $26.9 \mathrm{eV}$ in Figure 8(c) are characterized as $\mathrm{Taff}_{7 / 2}$ and $\mathrm{Ta} 4 \mathrm{f}_{5 / 2}$, respectively, indicating that the $\mathrm{Ta}^{5+}$ existed in the lattice. The sample with $x=0.1$ showed the broad peak of Ta $4 \mathrm{p}_{3 / 2}$ [14]. This indicates that an excess amount of $\mathrm{Ta}^{5+}$ doping might create crystal defects and/or lattice strain which may be the reason why this sample showed broad peak of N1s even though the highest nitrogen doping.

3.4. Photocatalytic Activity. Figure 9 shows the photocatalytic activity of $\mathrm{Ta}$ and $\mathrm{N}$ codoped $\mathrm{SrTiO}_{3}(x=0-$ 0.2 ) for the $\mathrm{NO}$ elimination under continuous irradiation by monochromatic lights of $390 \mathrm{~nm}$ (UV LED), $445 \mathrm{~nm}$ (blue LED), $530 \mathrm{~nm}$ (green LED), and $627 \mathrm{~nm}$ (red LED) in wavelength. As expected, $\mathrm{Ta}$ and $\mathrm{N}$ codoped $\mathrm{SrTiO}_{3}$ $(x=0.02-0.05)$ showed excellent photocatalytic activity, even under visible light irradiation $(\lambda=530 \mathrm{~nm})$. The photocatalytic activities of $\mathrm{Ta}$ and $\mathrm{N}$ codoped $\mathrm{SrTiO}_{3}$ under visible light irradiation $(\lambda=530 \mathrm{~nm})$ changed with variation of the Ta content, that is, the $\mathrm{NO}_{x}$ elimination degree increased by doping with small fraction of $\mathrm{Ta}(x=0.02-$ 0.05 ), but decreased by doping with an excess amount of Ta. Excess $\mathrm{Ta}^{5+}$ doping might lead to the formation of cation defect and/or reduction of $\mathrm{Ti}^{4+}$ to $\mathrm{Ti}^{3+}$ for the charge compensation which acts as a recombination site of photoinduced electrons and holes to decrease the photocatalytic activity [15]. These results agree with the PL measurement shown in Figure 7. For the sample of nitrogen-doped $\mathrm{SrTiO}_{3}$ $(x=0)$, the photocatalytic activity in visible light $(\lambda=$ $530 \mathrm{~nm}$ ) is higher than that of the standard titania (Degussa P25), although nitrogen doping could not be clearly observed by XPS. The higher activity under irradiation of visible light may be partly contributed by the codoped carbon, which is attributed to chemically adsorbed oleic acid on the surface.

\section{Conclusions}

Nanoparticles of ca. $20 \mathrm{~nm}$ in diameter of Ta and $\mathrm{N}$ codoped $\mathrm{SrTiO}_{3}, \mathrm{SrTi}_{1-x} \mathrm{Ta}_{x} \mathrm{O}_{3-y} \mathrm{~N}_{y}(x=0,0.02,0.05$ and 0.1$)$ were synthesized by solvothermal reactions in $\mathrm{KOH}$ and oleic acid mixed methanol solutions using $\mathrm{Ti}\left(\mathrm{OC}_{3} \mathrm{H}_{7}\right)_{4}, \mathrm{SrCl}_{2} \cdot 6 \mathrm{H}_{2} \mathrm{O}$, $\mathrm{TaCl}_{5}$, and HMT (hexamethylentetramine) as the starting materials. $\mathrm{SrTa}_{x} \mathrm{Ti}_{1-x} \mathrm{O}_{3-y} \mathrm{~N}_{y}$ showed excellent photocatalytic activity for the oxidative destruction of $\mathrm{NO}$ under visible light irradiation $(\lambda>530 \mathrm{~nm})$. The photocatalytic activity changed depending on the tantalum content. The optimum Ta content was determined to be $x=0.02-0.05$.

\section{Acknowledgment}

This research was partly supported by the Management Expenses Grants for National Universities Corporations from the Ministry of Education, Culture, Sports, Science and Technology of Japan (MEXT).

\section{References}

[1] M. R. Hoffmann, S. T. Martin, W. Choi, and D. W. Bahnemann, "Environmental applications of semiconductor photocatalysis," Chemical Reviews, vol. 95, no. 1, pp. 69-96, 1995.

[2] A. L. Linsebigler, G. Lu, and J. T. Yates, "Photocatalysis on $\mathrm{TiO}_{2}$ surfaces: principles, mechanisms, and selected results," Chemical Reviews, vol. 95, no. 3, pp. 735-758, 1995.

[3] U. Sulaeman, S. Yin, and T. Sato, "Solvothermal synthesis of designed nonstoichiometric strontium titanate for efficient visible-light photocatalysis," Applied Physics Letters, vol. 97, no. 10, Article ID 103102, 2010.

[4] J. Wang, S. Yin, M. Komatsu, Q. Zhang, F. Saito, and T. Sato, "Preparation and characterization of nitrogen doped $\mathrm{SrTiO}_{3}$ photocatalyst," Journal of Photochemistry and Photobiology A, vol. 165, no. 1-3, pp. 149-156, 2004.

[5] T. Sato, U. Sulaeman, and S. Yin, "Solvothermal synthesis and photocatalytic properties of nitrogen-doped $\mathrm{SrTiO}_{3}$ nanoparticles," Journal of Nanomaterials, vol. 2010, Article ID 629727, 6 pages, 2010.

[6] K. Obata, H. Irie, and K. Hashimoto, "Enhanced photocatalytic activities of Ta, $\mathrm{N}$ co-doped $\mathrm{TiO}_{2}$ thin films under visible light," Chemical Physics, vol. 339, no. 1-3, pp. 124-132, 2007.

[7] U. Sulaeman, S. Yin, T. Suehiro, and T. Sato, "Solvothermal synthesis of $\mathrm{SrTiO}_{3}-\mathrm{LnTiO}_{2} \mathrm{~N}$ solid solution and their visible light responsive photocatalytic properties," IOP Conference Series: Material Science and Engineering, vol. 1, no. 1, Article ID 012017, 2009.

[8] W. Wang, W. Zhu, and H. Xu, "Monodisperse, mesoporous $\mathrm{Zn}_{\mathrm{x}} \mathrm{Cd}_{1-\mathrm{x}} \mathrm{S}$ nanoparticles as stable visible-light-driven photocatalysts," Journal of Physical Chemistry C, vol. 112, no. 43, pp. 16754-16758, 2008.

[9] C. W. Kim, H. G. Cha, Y. H. Kim et al., "Surface investigation and magnetic behavior of Co nanoparticles prepared via a surfactant-mediated polyol process," Journal of Physical Chemistry C, vol. 113, no. 13, pp. 5081-5086, 2009.

[10] S. Yin, B. Liu, P. Zhang, T. Morikawa, K. I. Yamanaka, and T. Sato, "Photocatalytic oxidation of $\mathrm{NO}_{\mathrm{x}}$ under visible led light irradiation over nitrogen-doped titania particles with iron or platinum loading," Journal of Physical Chemistry C, vol. 112, no. 32, pp. 12425-12431, 2008.

[11] H. Yang, K. Kan, J. Ouyang, and Y. Li, "Solvothermal synthesis and optical properties of $\mathrm{Mn}^{2+}$-doped $\mathrm{SrTiO}_{3}$ powders," Journal of Alloys and Compounds, vol. 485, no. 1-2, pp. 351355, 2009.

[12] J. Wang, S. Yin, M. Komatsu, and T. Sato, "Lanthanum and nitrogen co-doped $\mathrm{SrTiO}_{3}$ powders as visible light sensitive photocatalyst," Journal of the European Ceramic Society, vol. 25, no. 13, pp. 3207-3212, 2005.

[13] E. B. Varhegyi, S. Jonda, I. V. Perczel, and H. Meixner, "AES, SIMS, XPS analysis and electrical conductance of Ta-doped $\mathrm{SrTiO}_{3}$ thin films," Sensors and Actuators B, vol. 47, no. 1-3, pp. 164-170, 1998.

[14] C. B. Kaynak, M. Lukosius, I. Costina et al., "Investigations of thermal annealing effects on electrical and structural properties of SrTaO based MIM capacitor," Microelectronic Engineering, vol. 87, no. 12, pp. 2561-2564, 2010.

[15] T. Torimoto, R. J. Fox III, and M. A. Fox, "Photoelectrochemical doping of $\mathrm{TiO}_{2}$ particles and the effect of charge carrier density on the photocatalytic activity of microporous semiconductor electrode films," Journal of the Electrochemical Society, vol. 143, no. 11, pp. 3712-3717, 1996. 

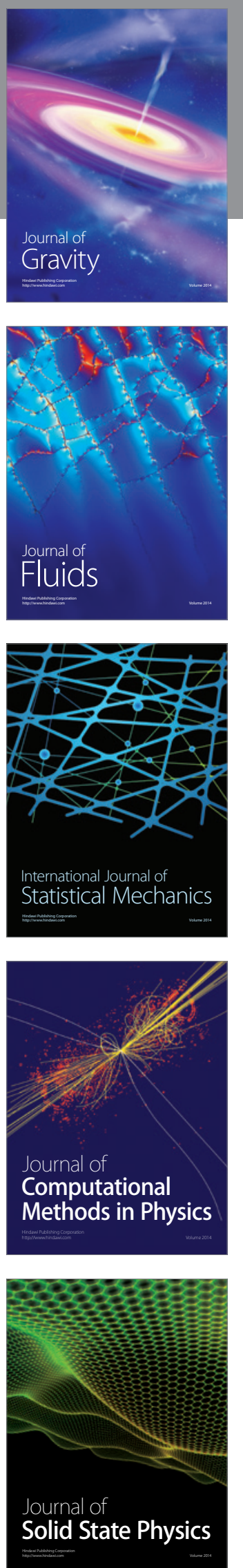

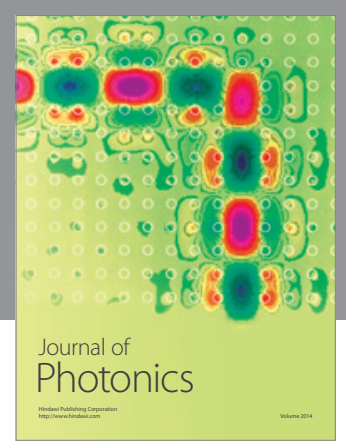

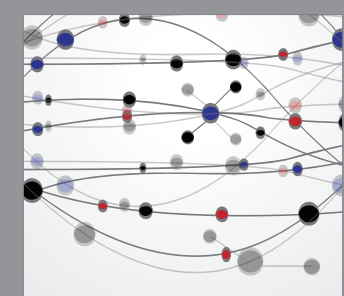

The Scientific World Journal
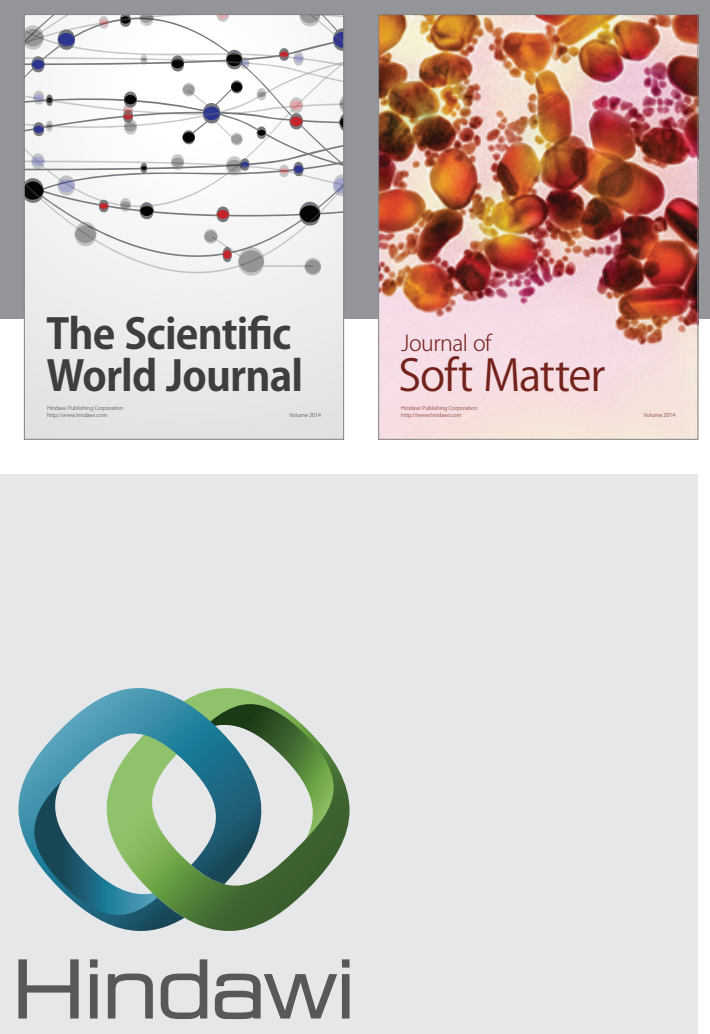

Submit your manuscripts at

http://www.hindawi.com
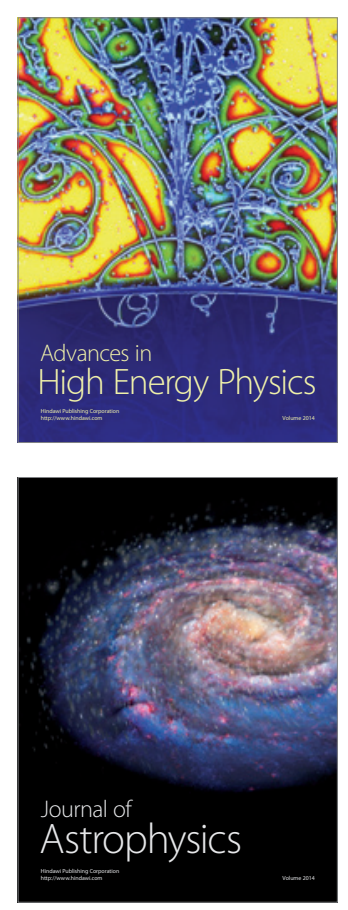
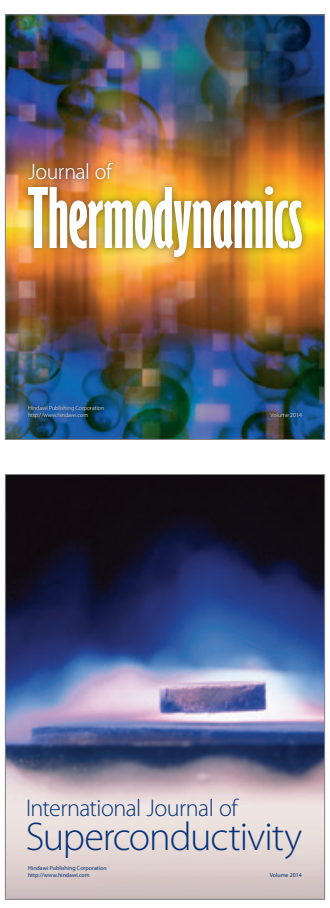
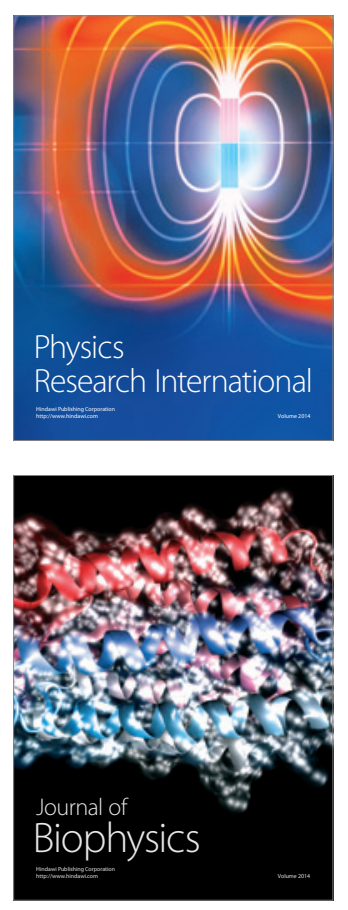
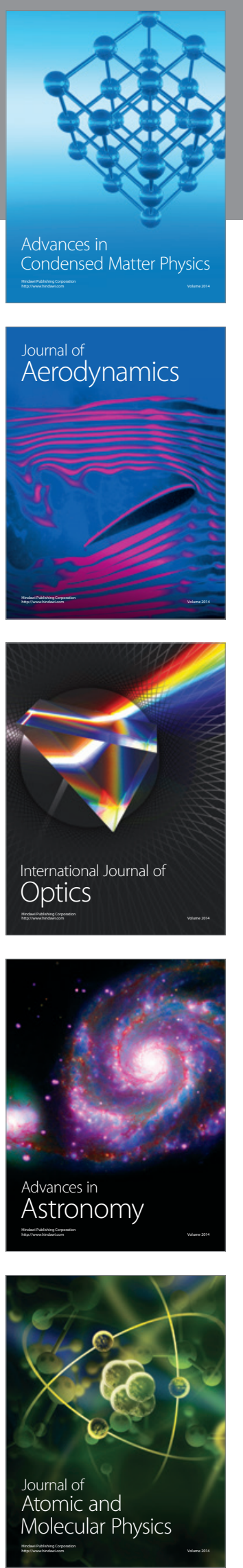